\title{
NEW RAPID ANALYSIS OF TWO CLASSES OF PESTICIDES IN FOOD WASTEWATER BY QUECHERS-LIQUID CHROMATOGRAPHY/MASS SPECTROMETRY
}

\author{
Bożena Łozowicka', Piotr Kaczyński', Julia Szabuńko', Katarzyna Ignatowicz², \\ Dariusz Warentowicz ${ }^{2}$, Jakub Łozowicki ${ }^{2}$
}

\author{
1 Plant Protection Institute - National Research Institute, Laboratory of Pesticide Residues, Chelmonskiego 22, \\ 15-195 Bialystok, Poland, e-mail: B.Lozowicka@iorpib.poznan.pl \\ 2 Bialystok University of Technology, Wiejska 45, 15-351 Bialystok, Poland
}

Received: 2016.03.16 Accepted: 2016.06.01 Published: 2016.07.01

\begin{abstract}
The rapid analytical method was developed in response to increasing concern over the environmental impact of azoles (sterol biosynthesis inhibitors) and neonicotinoids (nicotinic acetylcholine receptor site). These chemicals are commonly used to protect fruit and vegetables crops against fungi and pests. Seven insecticides and twenty one fungicides commonly occurring in food industrial wastewater have been determined. For this purpose, active substances from two new pesticide classes were extracted and isolated by QuEChERS by addition of acetonitrile, buffering salts and chitin as a clean-up sorbent. The novelty of this procedure was one step sample preparation including extraction and removing of co-extracts in short time. Instrumental analysis was conducted by liquid chromatography coupled with mass spectrometry using multiple reaction monitoring. The limits of detection ranged from 0.002 to $0.005 \mu \mathrm{g} \cdot \mathrm{L}^{-1}$ with satisfactory accuracy and precision The recoveries for the pesticides ranged from $81-103 \%$, with high repeatability $(\mathrm{n}=3, \mathrm{RSD} \leq 9 \%)$ and low LOQs $\left(0.01 \mu \mathrm{g} \cdot \mathrm{L}^{-1}\right)$. Matrix effects calculated were less than $12 \%$ for all analyses. The method was applied to routine analysis of food industrial wastewater. Concerning the results, total pesticide levels in most cases were below $1 \mu \mathrm{g} \cdot \mathrm{L}^{-1}$. The most significant pesticides in terms of concentration and frequency of detection were acetamiprid $\left(0.07 \mu \mathrm{g} \cdot \mathrm{L}^{-1}\right)$; tebuconazole $\left(1.2 \mu \mathrm{g} \cdot \mathrm{L}^{-1}\right)$ and thiacloprid $\left(0.04 \mu \mathrm{g} \cdot \mathrm{L}^{-1}\right)$.
\end{abstract}

Keywords: wastewater, azole, neonicotinoids, QuEChERS, LC-MS/MS

\section{INTRODUCTION}

Typically, fruit and vegetable industry produce large amounts of wastes. These wastes include solids (i.e., peels, cores, seeds, stems, dirt, etc.) and liquids (i.e., juices, wash water, chilling water, cleaners, sanitizers, etc.). Disposing these wastes generally requires permits from regional environmental agencies to ensure minimal environmental impact. The volume and the quality of the water from recycling facilities highly depend on the product and season. The preservation of fruit and vegetables is achieved by canning, drying, or freezing, and by the preparation of juices, jams and jellies. The main steps include the preparation of the raw material (cleaning, trimming, and peeling) and cooking, canning, and freezing. Approximately $50 \%$ of water in fruit and vegetable processing is used for washing and rinsing [Environ Poland, 2004].

Wastewater characteristics greatly depend upon the type of fruit or vegetable processed and the processing techniques used (e.g., washing, blanching, peeling, etc.). Before being dis- 
charged, wastewater needs additional treatment to reduce such components as TSS, FOG, COD, TKN, total phosphorous [Nawirska A., 2007].

The wastes, among different impurities, very often contain pesticide residues washed from the raw materials. Chemical pesticides are extensively used in fruit and vegetable cultivation in order to obtain better quality and yields of crops [Skoczko I., 2009]. The presence of such a large number of pesticide pollution in the wastewater requires effective and economical analytical methods for pesticide control.

Azoles are synthetic antifungal compounds derived from triazole or imidazole. Azole-derivatives are used for control of fungal pathogens in plants. Thousands of tons of azoles are sold annually for the purpose of plant protection [FAO, 2012]. The main advantages are their broad spectrum of antifungal activity and their relatively long persistence. Mixtures of azoles are considered of interest for disease control because they prevent unidirectional selection and may both stabilize phenotypes with reduced sensitivity and optimize resistance management strategies [EPPO Workshop, 2010]. Besides the concern for worker exposure, their large use in agriculture and their presence as residues in certain food items carry the potential for human exposure to individual or multiple compounds [Hof H., 2001; EFSA, 2009a].

Neonicotinoids are a new class of insecticides chemically related to nicotine. The neonicotinoids act on certain kinds of receptors in the nerve synapse and they are much more toxic to insects, than they are to mammals, birds and other higher organisms. Neonicotinoids are important as they provide an alternative mode of action to organophosphate and pyrethroid insecticides. This allows them to play a key role in helping to prevent the build up of resistance in the pests concerned. Neonicotinoids insecticides are popular in pest control because of their water solubility, which allows them to be applied to soil and be taken up by plants. There are several different kinds of neonicotinoids insecticides [BASF, 2013]. The first neonicotinoids to reach the market was imidacloprid, a common ingredient in Bayer Advanced Garden insecticides. This product can be sprayed on the plant, but is often more effective (especially on sucking insects) when applied to the soil [TLC, 2012]. Initially neonicotinoids were praised for their low-toxicity to many beneficial insects, including bees; however, recently this claim has come into question. New research points to potential toxicity to bees and other beneficial insects through low level contamination of nectar and pollen with neonicotinoid insecticides used in agriculture.

Many techniques can be used for the determination of pesticide compounds in wastewater. A review of the literature showed that methods such as liquid-liquid extraction [Kuranchie-Mensah et al., 2012] or solid-phase extraction [Singer et al., 2010; El-Kabbany et al., 2000; Al-Degs et al., 2009] coupled to LC-MS/MS, GC-MS and HPLC-UV or GC-ECD are commonly used. Solid-phase extraction technique has many modifications, for example: soil-phase microexstraction (SPME) [Silva et al., 2015; Bonansea et al., 2013], HF-SPME (hollow fiber solid-phase microextraction) [Ebrahimi et al., 2011] and stir bar sorptive extraction followed by liquid desorption (SBSE-LD) [Margoum et al., 2013]. Other sample prepartion methods based on solvent demulsification dispersive liquid-liquid microextraction (SDDLLME) [Souza Caldas et al., 2016], extraction using tannic acid azo polyurethane sorbent (PUFazo-Tan) [Moawed et al., 2015] or electrochemical method using a boron-doped diamond electrode [Svorc, 2013].

According to our best knowledge, no scientific reports describing QuEChERS method as sample preparation of wastewater in pesticide analysis. The goal of this study was to apply QuEChERS method for trace levels for determination of two new classes of pesticides including azoles and nenicotinides.

The novelty of this method was one step sample preparation including extraction and removing of co-extracts in short time and application validated methods to wastewater real samples.

\section{MATERIALS AND METHODS}

\section{Materials and reagents}

The 28 pesticide standards were purchased from Dr. Ehrenstorfer Laboratory (Augsburg, Germany) with purities ranged from $96.0 \%$ to $99.8 \%$.

Formic acid and ammonium formate were purchased from Merck (Darmstadt, Germany). LC-MS grade methanol was purchased from POCh (Gliwice, Poland) and LC-grade water $(18 \mathrm{M} \Omega \mathrm{cm})$ from a MilliQ water purification system (Millipore Ltd., Bedford, MA, USA). Mag- 
nesium sulphate, sodium chloride, sodium citrate dibasic sesquihydrate, sodium citrate tribasic dehydrate were purchased from Agilent Technologies (Santa Clara, USA) and Chitin from SigmaAldrich (Steinheim, Germany).

\section{Preparation of standards}

Stock solutions of pesticides (around 1000 $\mu \mathrm{g} \mathrm{mL}^{-1}$ ) were prepared separately by dissolving an accurately weighed amount of each reference standard in acetone. The combined working standard solutions were generated by serial dilution of the stock solutions with the same solvent. The working standard solutions were used for the preparation of matrix-matched standards within the concentration range of $0.005-2.0 \mu \mathrm{g} \mathrm{mL} \mathrm{L}^{-1}$ and for the spiking of samples in the validation studies. All the stock and working standard solutions and IS was stored in freezer at about $-20^{\circ} \mathrm{C}$ until analysis.

\section{Sample preparation}

Ten milliliters of wastewater sample ( $\mathrm{pH} 4)$ was transferred into a $50 \mathrm{~mL}$ disposable polypropylene centrifuge tube and $10 \mathrm{~mL}$ of acetonitrile was added. The tubes were immediately shaken for $1 \mathrm{~min}$. Then $4 \mathrm{~g}$ anhydrous magnesium sulphate, $1 \mathrm{~g}$ sodium chloride, $1 \mathrm{~g}$ trisodium citrate dihydrate and $0.5 \mathrm{~g}$ disodium hydrogen citrate sesquehydrate and $1 \mathrm{~g}$ of chitin were added. The tubes were immediately shaken for $5 \mathrm{~min}$ and then centrifuge for $5 \mathrm{~min}$ at $4500 \mathrm{rpm}$. One $\mathrm{ml}$ of the extract was filtered through a $0.2 \mu \mathrm{m}$ hydrophilic PTFE filter, transferred into the autosampler vial and analyzed via LC/MS/MS (Figure 1).

\section{LC-MS/MS conditions}

An Eksigent Ultra LC-100 (Eksigent Technologies, Dublin, CA, USA) liquid chromatography system was operated at a flow rate of
$0.35 \mathrm{~mL} \mathrm{~min}^{-1}$ without split using a SunFire C18 $2.5 \mu \mathrm{m}, 2.1 \times 75 \mathrm{~mm}$ (Waters) analytical column, maintained at $40{ }^{\circ} \mathrm{C}$ during the experiments. The volume injected into the LC/MS/MS system was $10 \mu \mathrm{L}$. The binary mobile phase consisted of water with $0.5 \%$ formic acid and $2 \mathrm{mM}$ ammonium formate (phase A) and methanol with $0.5 \%$ formic acid and $2 \mathrm{mM}$ ammonium formate (phase B). The gradient elution starting at 99\% A and 9\% $\mathrm{B}$ was held for $1.0 \mathrm{~min}$, rising linearly to $10 \% \mathrm{~A}$ and $90 \% \mathrm{~B}$ in $5.5 \mathrm{~min}$ and was held for $3.5 \mathrm{~min}$. After ramping, the mobile phase composition was returned to the initial condition in $1 \mathrm{~min}$, and this was held for $4 \mathrm{~min}$ for re-equilibration.

System MS/MS 6500 QTRAP (AB Sciex Instruments, Foster City, CA) was used for mass spectrometric analysis, equipped with an electrospray ionization source (ESI). The capillary voltage was maintained at $5000 \mathrm{~V}$ for positive ion mode and the temperature of the turbo heaters was set at $450{ }^{\circ} \mathrm{C}$. As the nebulizer gas (GS1), auxiliary gas (GS2) and curtain gas (CUR) the nitrogen was used at a pressure of 55, 45 and $35 \mathrm{psi}$ respectively. As the nebulizer and collision gas nitrogen was used, too. All pesticides were detected in the multiple reaction monitoring mode (MRM). One product ion for quantification and one for qualification. The MRM transitions for the pesticides are given in Table 1 .

\section{Validation study}

The developed method was subjected to validation study using wastewater (previously checked to be free of the target pesticides) in order to determine linearity, recovery, precision, limit of quantification (LOQ), matrix effects (ME) and uncertainty.

The linearity of the method was determined by analysis of a series of standard samples with five different concentrations in pure solvent and in matrix of sewage on three consecutive days.
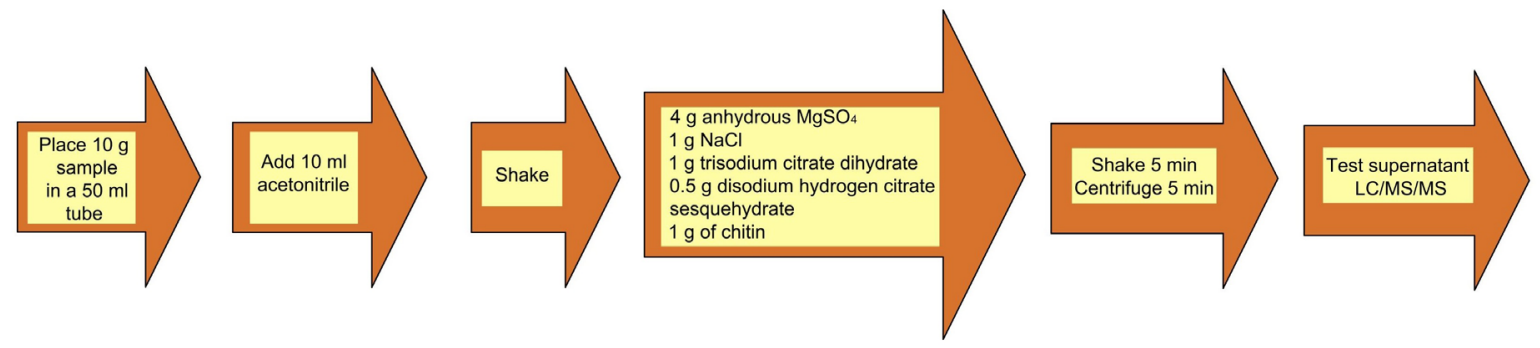

Figure 1. One step procedure of extraction and clean up for determination of two classes pesticides. 
Table 1. Optimised parametres of analysis LC-MS/MS of two classes pesticides.

\begin{tabular}{|c|c|c|c|c|c|c|c|c|c|c|c|}
\hline \multirow{2}{*}{$\begin{array}{l}\text { No of } \\
\text { sample }\end{array}$} & \multirow{2}{*}{ Active substance } & \multirow{2}{*}{$\begin{array}{l}\text { Retention } \\
\text { time [min] }\end{array}$} & \multicolumn{4}{|c|}{ Quantification } & \multicolumn{4}{|c|}{ Confirmation } & \multirow{2}{*}{$\begin{array}{l}\mathrm{EP} \\
{[\mathrm{V}]}\end{array}$} \\
\hline & & & $\begin{array}{c}\text { MRM transition } \\
\mathrm{m} / \mathrm{z}\end{array}$ & $\begin{array}{l}\text { DP } \\
{[V]}\end{array}$ & CE [V] & $\begin{array}{l}\text { CXP } \\
{[V]}\end{array}$ & $\begin{array}{c}\text { MRM transition } \\
\mathrm{m} / \mathrm{z}\end{array}$ & $\begin{array}{l}\text { DP } \\
{[V]}\end{array}$ & $\begin{array}{l}\mathrm{CE} \\
{[\mathrm{V}]}\end{array}$ & $\begin{array}{l}\mathrm{CXP} \\
{[\mathrm{V}]}\end{array}$ & \\
\hline 1. & Acetamiprid & 4.35 & $223>125.9$ & 80 & 27 & 6 & $223>99$ & 80 & 51 & 5 & 10 \\
\hline 2. & Azaconazole & 5.15 & $300>159$ & 86 & 37 & 10 & $300>231$ & 86 & 23 & 12 & 10 \\
\hline 3. & Bromuconazole & 5.95 & $378>159$ & 91 & 35 & 10 & $378>70$ & 91 & 61 & 8 & 10 \\
\hline 4. & Clothianidin & 4.2 & $250>169$ & 6 & 19 & 10 & $250>132$ & 6 & 21 & 6 & 10 \\
\hline 5. & Cyproconazole & 5.9 & $292>70$ & 61 & 23 & 8 & $292>125$ & 61 & 45 & 6 & 10 \\
\hline 6. & Diclobutrazol & 6.4 & $328>69.9$ & 85 & 58 & 8 & $328.01>159$ & 85 & 48 & 8 & 10 \\
\hline 7. & Difenoconazole & 6.85 & $406>251$ & 96 & 35 & 14 & $406>188$ & 96 & 59 & 10 & 10 \\
\hline 8. & Diniconazole & 6.9 & $326.1>70.1$ & 25 & 63 & 8 & $326.1>158.9$ & 25 & 39 & 10 & 10 \\
\hline 9. & Epoxiconazole & 6.1 & $330>121$ & 61 & 27 & 6 & $330>101.1$ & 61 & 65 & 6 & 10 \\
\hline 10. & Etaconazole & 6.1 & $328.1>159$ & 61 & 37 & 10 & $328.1>123$ & 61 & 75 & 6 & 10 \\
\hline 11. & Fenbuconazole & 6.2 & $337>125.1$ & 96 & 35 & 8 & $337>70$ & 96 & 23 & 8 & 10 \\
\hline 12. & Flonicamid & 3.7 & $230>173.9$ & 81 & 25 & 10 & $230>147.9$ & 81 & 37 & 8 & 10 \\
\hline 13. & Fluquinconazole & 6.05 & $376>306.9$ & 26 & 35 & 18 & $376>349$ & 26 & 27 & 18 & 10 \\
\hline 14. & Flusilazole & 6.25 & $316.1>247$ & 26 & 25 & 14 & $316.1>165.1$ & 26 & 35 & 10 & 10 \\
\hline 15. & Hexaconazole & 6.7 & $314.1>70$ & 21 & 49 & 8 & $314.1>159$ & 21 & 37 & 10 & 10 \\
\hline 16. & Imibenconazole & 7.5 & $411.1>125.1$ & 86 & 43 & 8 & $411.1>171$ & 86 & 29 & 10 & 10 \\
\hline 17. & Imidacloprid & 4.15 & $256>209.1$ & 80 & 21 & 12 & $256>175.1$ & 80 & 27 & 10 & 10 \\
\hline 18. & Ipconazole & 6.95 & $334.1>70$ & 71 & 61 & 8 & $334.1>124.9$ & 71 & 57 & 6 & 10 \\
\hline 19. & Metconazole & 6.7 & $320.1>70$ & 56 & 63 & 8 & $320.1>124.9$ & 56 & 55 & 6 & 10 \\
\hline 20. & Nitenpyram & 2.8 & $271.1>126$ & 61 & 37 & 8 & $271.1>237$ & 61 & 25 & 11 & 10 \\
\hline 21. & Penconazole & 6.45 & $284>70$ & 56 & 21 & 8 & $284>158.9$ & 56 & 35 & 8 & 10 \\
\hline 22. & Propiconazole & 6.5 & $342>159$ & 100 & 37 & 10 & $342>69$ & 100 & 23 & 8 & 10 \\
\hline 23. & Tebuconazole & 6.5 & $308.1>70$ & 41 & 57 & 8 & $308.1>125.1$ & 41 & 59 & 8 & 10 \\
\hline 24. & Tetraconazole & 6.1 & $372>159$ & 26 & 37 & 10 & $372>70$ & 26 & 73 & 10 & 10 \\
\hline 25. & Thiacloprid & 4.5 & $253>126$ & 96 & 29 & 6 & $253>72.9$ & 96 & 81 & 8 & 10 \\
\hline 26. & Thiamethoxam & 3.75 & $292>211$ & 61 & 17 & 12 & $292>181$ & 61 & 31 & 10 & 10 \\
\hline 27. & Triticonazole & 6.1 & $318>70$ & 71 & 49 & 8 & $318>125$ & 71 & 47 & 8 & 10 \\
\hline 28. & Uniconazole & 6.25 & $292.1>70$ & 106 & 59 & 10 & $292.1>125$ & 106 & 37 & 8 & 10 \\
\hline
\end{tabular}

For the recovery experiments, pesticides-free wastewater samples were spiked by the addition of appropriate volumes of representative standards of pesticides at three different levels. The mixture was left standing for $1 \mathrm{~h}$ to allow equilibration and was then processed according to the procedure described above. For each fortification level, five replicate samples were analyzed. Precision was expressed in terms of relative standard deviation (RSD) and calculated for each spiking level.

To evaluate the percent of matrix effects (\%ME) for each analyte, the slopes of the calibration curve obtained were used, at the same concentration levels which were determined by comparing solvent and matrix-matched calibration curves in terms of slope ratios according to formula: $\% \mathrm{ME}=\left(\right.$ slope $_{\text {matrix }} /$ slope $\left._{\text {solvent }}-1\right) \cdot 100$.
The measurement uncertainty was estimated based on the data obtained in the validation study. The relative expanded uncertainty was calculated by using the coverage factor $\mathrm{k}=2$ at the confidence level of $95 \%$.

\section{RESULT AND DISCUSSION}

\section{Validation study}

A series of experiments with regard to linearity, recovery, precision, limit of detection (LOD), limit of quantification (LOQ) and uncertainty (U) were performed to validate one-step extractioncleanup method under optimized conditions by using wastewater samples (previously checked to be free of the target pesticides). 
Linearity of calibration curves was studied by LC-MS/MS analysis of six calibration solutions at the pesticides concentrations of $0.005,0.01$, $0.05,0.1,0.5$ and $2.0 \mu \mathrm{g} \mathrm{mL}^{-1}(\mathrm{n}=3)$ in wastewater extracts (Figure 2). The linear regression data and satisfactory correlation coefficients for the 7 neonicotinoids and 21 azoles were obtained ranging from 0.99967 to 0.99999 are listed in Table 2 .

The recoveries were determined in five repetitions at the three spiking levels: $0.01,0.1$ and $2 \mu \mathrm{g} \mathrm{mL}^{-1}$. The level of quantification (LOQ) was defined as the lowest spiking level validated with satisfactory values of recovery (70-120\%) and RSD ( $\leq 20 \%)$ [Sanco, 2013].

All of the compounds are presented satisfactory recoveries in the range between $75 \%$ and $128 \%$. Only nitenpyram at the three concentration level $\left(0.01-2 \mu \mathrm{g} \mathrm{mL}^{-1}\right)$ showed recoveries values insignificantly outside the acceptance range $-121 \%$. All the pesticides gave a RSD lower than $24 \%$. Generally, at three fortification levels the RSD didn't exceed $15 \%$, except for nitenpyram (24\%).

The LOD values of individual pesticides were calculated based on the noise level in the chromatograms at $\mathrm{S} / \mathrm{N}$ of $3: 1$ and results are shown in Table 2. The limit of quantification (LOQ) was set at the lowest spiking concentration and for all the analytes $0.01 \mu \mathrm{g} \mathrm{mL^{-1 }}$ was accepted as the practical LOQ.

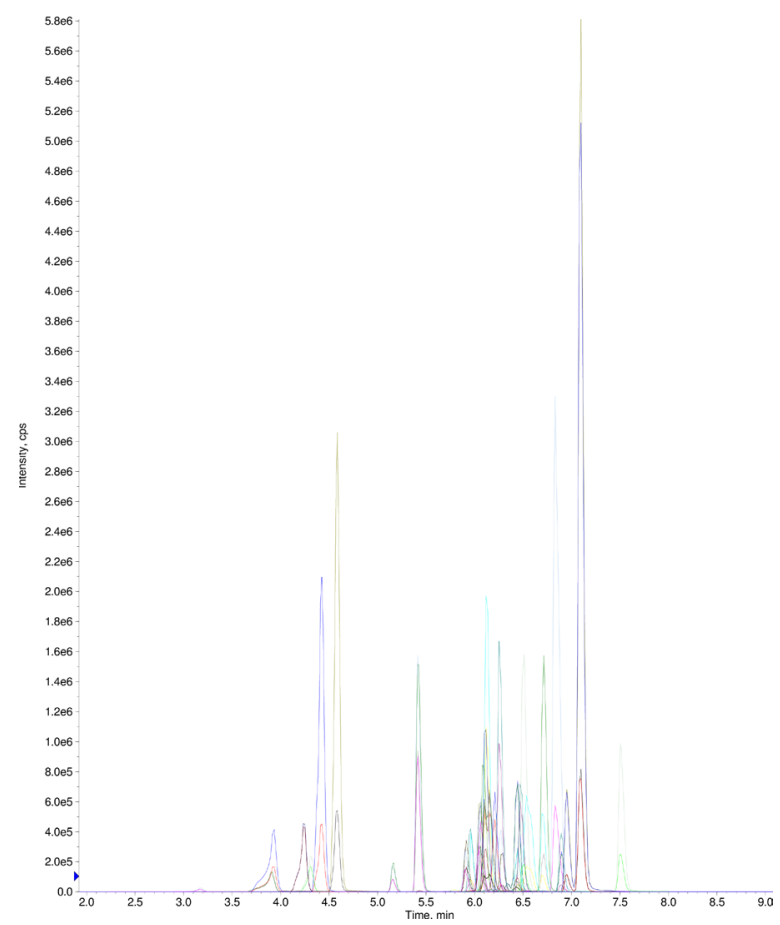

Figure 2. LC-MS/MS chromatogram of wastewater sample fortificated at $0.1 \mu \mathrm{g} \mathrm{L}^{-1}$ level.
The data derived from the validation study were used to estimate the measurement uncertainty (U) associated with the analytical results. The expanded measurement uncertainties were estimated employing a "top-down" empirical model [Medina-Pastor et al., 2011] as being between $9-28 \%$ (coverage factor $\mathrm{k}=2$, confidence level 95\%).

The precision was identified as the main contribution to the uncertainty. The uncertainty associated with the recovery, calculated from rectangular distribution, was also included in the uncertainty budget to avoid underestimation of the total uncertainty. The results are presented in Table 2, which clearly demonstrates suitability of the proposed method.

\section{Matrix effect}

Negative values of matrix effects signify suppression of the signal, and positive values signify enhancement [Kwon et al., 2012]. Twenty four of the target pesticides with $\mathrm{ME}$ in the acceptable range (-20-20\%) were obtained using chitin as a clean up sorbent (Table 2). Two compounds etaconazole and ipconazole ( ME -26\%) had matrix effect below $-20 \%$, and diclobutrazol, imibenconazole and propiconazole (ME 22\% and 24\%) above $20 \%$.

\section{Extraction and clean up step}

The QuEChERS method for pesticide residues analysis was first introduced by USDA scientists in 2003 year [Anastassiades et al., 2003]. The method was modified to address problematic pesticides, resulting in the official methods AOAC 2007.01 [Lehotay et al., 2005] and EN method 15662, a European variation of the QuEChERS method [CEN/TC, 2007; Paya et al., 2007] In summary, these methods consist from a three step: extraction, dispersive SPE and analysis. For the first extraction stage acetonitrile is added to the sample and various salts: anhydrous magnesium sulphate, $\mathrm{NaCl}$ and buffering citrate. The second step in above procedures based on dispersive solid phase extraction (d-SPE), used to minimize matrix effects with various combination depends on character of murices: of primary secondary amine (PSA) to remove organic acids, C18 for fat and lipid removal, GCB (graphitized carbon black) for pigment removal, and anhydrous magnesium sulphate to reduce remaining water in extract. 
Table 2. Validation parameters for 28 pesticides in wasterwater matrix.

\begin{tabular}{|c|c|c|c|c|c|c|c|c|}
\hline \multirow{2}{*}{ Pesticide } & \multicolumn{3}{|c|}{ Recovery (RSD) [\%] } & \multirow{2}{*}{$\mathrm{ME}[\%]$} & \multirow{2}{*}{$\mathrm{R}^{2}$} & \multirow{2}{*}{$\begin{array}{c}\mathrm{LOD} \\
{\left[\mu \mathrm{L} \mathrm{L}^{-1}\right]}\end{array}$} & \multirow{2}{*}{$\begin{array}{c}\mathrm{LOQ} \\
{\left[\mu \mathrm{g} \mathrm{L}^{-1}\right]}\end{array}$} & \multirow{2}{*}{$\cup[\%]$} \\
\hline & $0.01 \mu \mathrm{g} \mathrm{L}^{-1}$ & $0.1 \mu \mathrm{g} \mathrm{L}^{-1}$ & $2.0 \mu \mathrm{g} \mathrm{L}^{-1}$ & & & & & \\
\hline Acetamiprid & $83(6)$ & $92(7)$ & $94(8)$ & -13 & 0.99999 & 0.004 & 0.01 & 16 \\
\hline Azaconazole & $75(7)$ & $83(6)$ & $86(7)$ & -9 & 0.99982 & 0.005 & 0.01 & 17 \\
\hline Bromuconazole & $78(8)$ & $83(7)$ & $82(8)$ & 9 & 0.99986 & 0.003 & 0.01 & 15 \\
\hline Clothianidin & $89(9)$ & $91(11)$ & $94(10)$ & -15 & 0.99992 & 0.002 & 0.01 & 20 \\
\hline Cyproconazole & $80(7)$ & $84(8)$ & $81(8)$ & -3 & 0.99997 & 0.003 & 0.01 & 9 \\
\hline Diclobutrazol & $99(9)$ & $93(6)$ & $82(7)$ & 22 & 0.99967 & 0.003 & 0.01 & 18 \\
\hline Difenoconazole & $82(5)$ & $80(7)$ & $82(6)$ & -15 & 0.99989 & 0.005 & 0.01 & 10 \\
\hline Diniconazole & $96(4)$ & $98(5)$ & $94(5)$ & 14 & 0.99992 & 0.003 & 0.01 & 9 \\
\hline Epoxiconazole & $89(6)$ & $94(6)$ & $97(5)$ & -15 & 0.99991 & 0.002 & 0.01 & 13 \\
\hline Etaconazole & $84(4)$ & $98(5)$ & $94(6)$ & -26 & 0.99999 & 0.005 & 0.01 & 15 \\
\hline Fenbuconazole & $87(5)$ & $98(6)$ & $96(7)$ & 10 & 0.99996 & 0.003 & 0.01 & 17 \\
\hline Flonicamid & $86(6)$ & $91(5)$ & $92(6)$ & -14 & 0.99988 & 0.005 & 0.01 & 14 \\
\hline Fluquinconazole & $92(5)$ & $96(9)$ & $101(9)$ & 20 & 0.99993 & 0.002 & 0.01 & 19 \\
\hline Flusilazole & $109(11)$ & $104(14)$ & $110(12)$ & -20 & 0.99998 & 0.003 & 0.01 & 21 \\
\hline Hexaconazole & $96(6)$ & $93(7)$ & $97(6)$ & -14 & 0.99978 & 0.003 & 0.01 & 14 \\
\hline Imibenconazole & $94(7)$ & $88(5)$ & $99(6)$ & 24 & 0.99999 & 0.004 & 0.01 & 18 \\
\hline Imidacloprid & $80(10)$ & $94(12)$ & $100(11)$ & -11 & 0.99985 & 0.002 & 0.01 & 25 \\
\hline Ipconazole & $83(12)$ & $91(14)$ & $94(15)$ & -26 & 0.99998 & 0.004 & 0.01 & 24 \\
\hline Metconazole & $98(4)$ & $102(5)$ & $104(6)$ & 13 & 0.99996 & 0.003 & 0.01 & 14 \\
\hline Nitenpyram & $128(20)$ & $119(21)$ & $122(24)$ & -10 & 0.99998 & 0.005 & 0.01 & 28 \\
\hline Penconazole & $87(6)$ & $98(6)$ & $106(7)$ & -8 & 0.99994 & 0.003 & 0.01 & 20 \\
\hline Propiconazole & $92(8)$ & $97(7)$ & $104(6)$ & 22 & 0.99997 & 0.003 & 0.01 & 17 \\
\hline Tebuconazol & $78(5)$ & $88(8)$ & $99(8)$ & -4 & 0.99996 & 0.003 & 0.01 & 19 \\
\hline Tetraconazole & $86(7)$ & $85(7)$ & $94(6)$ & -10 & 0.99988 & 0.003 & 0.01 & 17 \\
\hline Thiacloprid & $88(6)$ & $90(6)$ & $97(5)$ & 19 & 0.99996 & 0.003 & 0.01 & 16 \\
\hline Thiamethoxam & $79(8)$ & $89(7)$ & $101(8)$ & -1 & 0.99999 & 0.003 & 0.01 & 17 \\
\hline Triticonazole & $95(7)$ & $88(7)$ & $90(5)$ & -13 & 0.99994 & 0.003 & 0.01 & 15 \\
\hline Uniconazole & $80(8)$ & $96(5)$ & $92(4)$ & -18 & 0.99998 & 0.004 & 0.01 & 16 \\
\hline
\end{tabular}

In our one step proposal, acetonitrile is added to the sample followed by salting out of the water from the sample using anhydrous magnesium sulphate, $\mathrm{NaCl}$ and buffering citrate to introduce extraction partitioning and chitin as dispersive solid phase extraction (d-SPE) to remove organic acids, sugar, wax and lipids. Figure 3 shows total ion chromatograms of matrix-matched standard without cleanup (blue line) and after cleanup with chitin (red line).

Pesticide extraction in wastewater has been considered difficult due to complicated fruit/vegetable matrix and the critical point of proposed method was removed matrix impurities. The chitin added during extraction step yielded a cleaner extract, therefore it was chosen for the wastewater procedure. This natural sorbent, chitin, is excellent and minimizes matrix effect. QuEChERS is a very good sample extraction and clean up method that is suitable for broad varieties of pesticides. Our modification extraction and clean up steps were used for 28 pesticides analysis in fruit/ vegetable wastewater matrix.

Literature suggests using selective methods of detection of pesticides such groups as, for example: chlorinated hydrocarbons, organophosphates, triazines, chloroacetanilide, pyrethroids, carbamates, phthalimides from using GC - MS/ MS [Papadakis et al., 2015]. These selective detection methods are limited and specific for certain pesticides groups. In this work we demonstrated that liquid chromatography - mass spectrometry as a very good technique for determining the concentration of azoles and neonicotinoids in wastewater from fruit and vegetable processing. 


\section{Real samples application}

The wide range of compounds analyzed (Table 1), demonstrated the applicability of this method for identifying pesticide contaminants in wastewater samples.

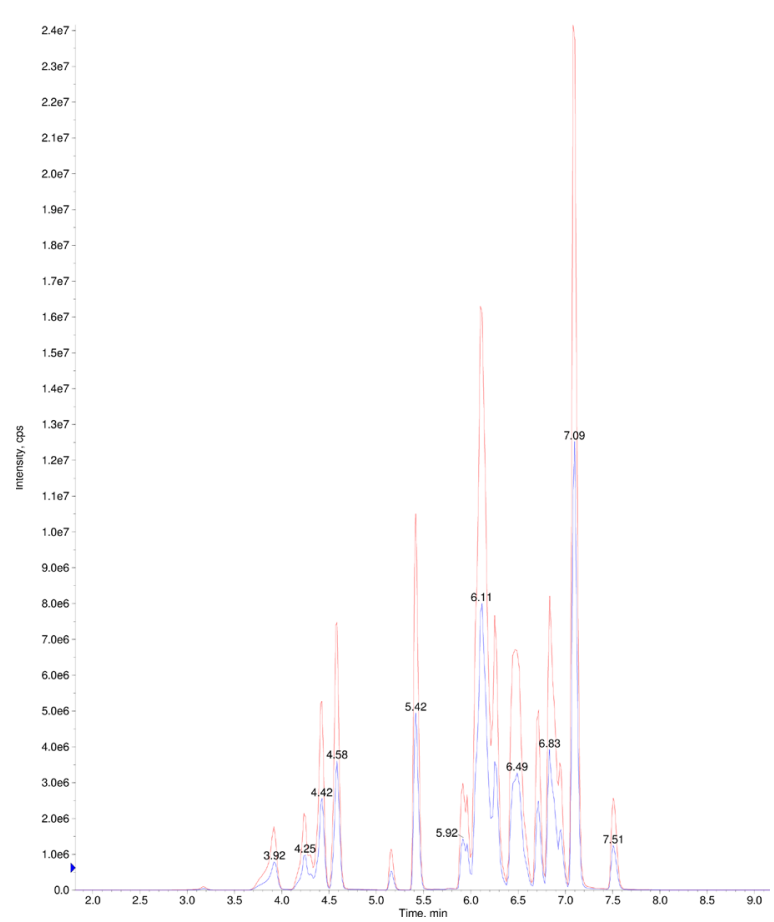

Figure 3. Total ion chromatograms of matrixmatched standard: without cleanup (blue line) and after cleanup (red line).

a)

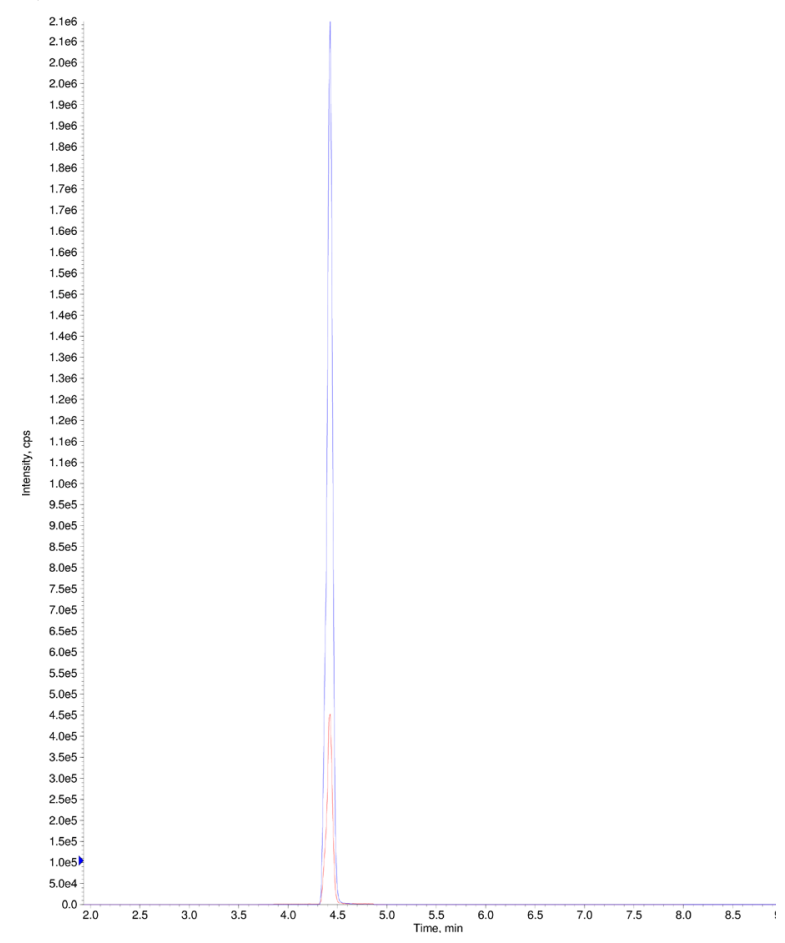

Developed and validated method was used for detection and identification of wasterwater. During the 2014-2015 years (between June - October) method was applied for the analysis of about 30 wasterwater samples from the fruit/vegetables food industry factory. Figure 4 shows chromatograms of real wastewater samples, one pesticide

b)

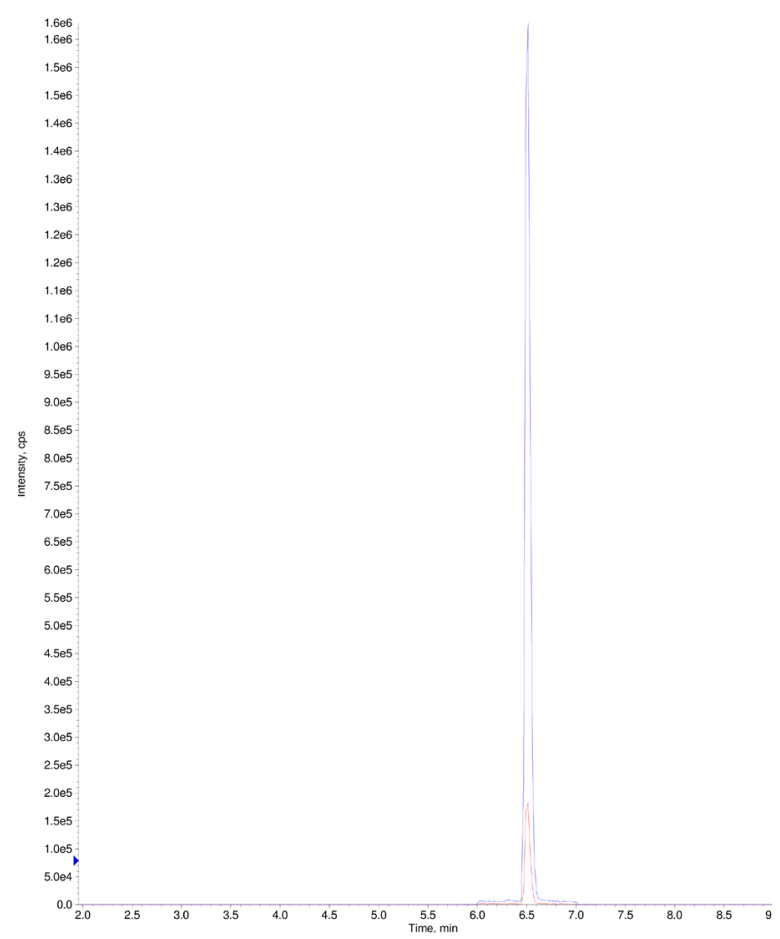

c)

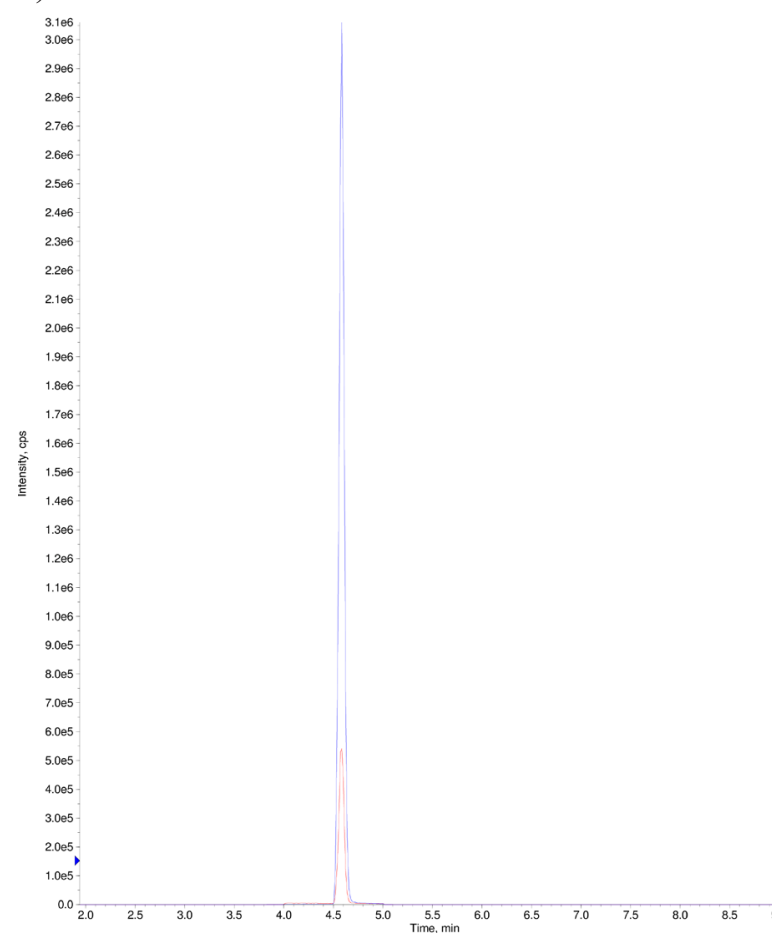

Figure 4. Chromatograms of real wastewater samples containing: a) acetamiprid $\left(0.07 \mu \mathrm{g} \mathrm{L}^{-1}\right)$; b) tebuconazole $\left(1.2 \mu \mathrm{g} \mathrm{L}^{-1}\right)$ and c) thiacloprid $(0.04 \mu \mathrm{g} \mathrm{L}-1)$. 
in each sample were detected: acetamiprid $(0.07$ $\left.\mu \mathrm{g} \mathrm{L}{ }^{-1}\right)$; tebuconazole $\left(1.2 \mu \mathrm{g} \mathrm{L}^{-1}\right)$ and thiacloprid $\left(0.04 \mu \mathrm{g} \mathrm{L}^{-1}\right)$. Therefore, this method can be used as a routine monitoring tool for azoles and neonicotinoids pesticides in food wastewater matrices.

\section{CONCLUSIONS}

1. Our one step QuEChERS method including extraction and clean up provided a simple, fast and effective method in wastewater samples.

2 . The recovery and reproducibility of two pesticide classes were acceptable for multiresidue determination in complexes matrices as wastewater.

3. The most common pesticides were acetamiprid, tebuconazole and thiacloprid.

\section{REFERENCES}

1. Al-Degs Y. S., Al-Ghouti M. A., El-Sheikh A. H., 2009. Simultaneous determination of pesticides at trace levels in water using multiwalled carbon nanotubes as solid-phase extractant and multivariate calibration. Journal of Hazardous Materials, $169,128-135$.

2. Anastassiades M., Lehotay S.J., Stajnbaher D, Schenck F.J., 2003. Fast and easy multiresidue method employing acetonitrile extraction/partitioning and "dispersive solid-phase extraction" for the determination of pesticide residues in produce. Journal of AOAC International, 86, 412-431.

3. BASF, 2013. Insecticide Mode of Action. BASF Crop Protection Division Global Strategic Marketing Insecticides, 23-26.

4. Bonansea R. I., Amé M. V., Wunderlin D. A., 2013. Determination of priority pesticides in water samples combining SPE and SPME coupled to GCMS. A case study: Suquía River basin (Argentina). Chemosphere, 90, 1860-1869.

5. CEN/TC, 2007. Foods of plant origin: Determination of pesticide residues using GC-MS and/or LC-MS/ MS following acetonitrile extraction/partitioning and cleanup by dispersive SPE QuEChERS method. European Committee for Standardization, Brussels, 275.

6. Ebrahimi M., Eshaghi Z., Samadi F., Hosseini M.S., 2011. Ionic liquid mediated sol-gel sorbents for hollow fiber solid-phase microextraction of pesticide residues in water and hair samples. Journal of Chromatography A, 1218, 8313-8321.

7. EFSA, 2009a. Scientific opinion on risk assessment for a selected group of pesticides from the triazole group to test possible methodologies to assess cumulative effects from exposure through food from these pesticides on human health. EFSA Journal, 7, 1167.

8. El-Kabbany S., Rashed M.M., Zayed M.A., 2000. Monitoring of the pesticide levels in some water supplies and agricultural land, in El-Haram, Giza (A.R.E.). Journal of Hazardous Materials, A72, 11-21.

9. ENVIRON Poland, 2004. The best available techniques (BAT) - guidelines for the food industry: fruit - vegetables. Ministry of the Environment, Warsaw.

10. EPPO Workshop, 2010. Workshop on Azole fungicides and Septoria leaf blotchcontrol Conference Centre, Rothamsted Research, Harpenden(GB), 2010-12-07/09.

11. FAO FAOSTAT , 2012. http : // faostat.fao.org / site / 424 / DesktopDefault.aspx ? Page ID $=424$ \# ancor (accessed 14.02.13).

12. Hof H., 2001. Critical annotations to the use of azole antifungals forplant protection. Antimicrob Agents Chemother, 45, 2987-2990.

13. Kuranchie-Mensah H., Manukure Atiemo S., Maud Naa-Dedei Palm L., Blankson-Arthur S., Osei Tutu A., Fosu P., 2012. Determination of organochlorine pesticide residue in sediment and water from the Densu river basin, Ghana. Chemosphere, 86, 286-292.

14. Kwon H., Lehotay S.J., Geis-Asteggiante L., 2012. Variability of matrix effects in liquid and gas chromatography-mass spectrometry analysis of pesticide residues after QuEChERS sample preparation of different food crops. Journal of Chromatography A, 1270, 235-245.

15. Lehotay S.J., Mastovska K., Lightfield A.R., 2005. Use of buffering and other means to improve results of problematic pesticides in a fast and easy method for residue analysis of fruits and vegetables. Journal of AOAC International, 88(2), 615-629.

16. Margoum C., Guillemain C., Yang X., Coquery M., 2013. Stir bar sorptive extraction coupled to liquid chromatography-tandem mass spectrometry for the determination of pesticides in water samples: Method validation and measurement uncertainty. Talanta, 116, 1-7.

17. Medina-Pastor P., Valverde A., Pihlsotrm T., Masselter S., Gamon M., Mezcua M., Rodriguez-Torreblanca C., Fernandez-Alba A. R., 2011. Comparative study of the main top-down approaches for the estimation of measurement uncertainty in multiresidue analysis of pesticides in fruits and vegetables. Journal of Agricultural and Food Chemistry, 59, 7609-7619.

18. Moawed E.A., Abulkibash A.B., El-Shahat M.F., 2015. Synthesis of tannic acid azo polyurethane 
sorbent and its application for extraction and determination of atrazine and prometryn pesticides in foods and water samples. Environmental Nanotechnology, Monitoring and Management, 3, 61-66.

19. Nawirska A., 2007. Economy of water-sewage in the industry fruit-vegetable. Agro Industry, 3, 65-67.

20. Papadakis E. N., Vryzas Z., Kotopoulou A., Kintzikoglou K., Makris K. C., PapadopoulouMourkidou E., 2015. A pesticide monitoring survey in rivers and lakes of northern Greece and its human and ecotoxicological risk assessment. Ecotoxicology and Environmental Safety, 116, 1-9.

21. Payá P., Anastassiades M., Mack D., Sigalova I., Tasdelen B., Oliva J., Barba A., 2007. Analysis of pesticide residues using the Quick Easy Cheap Effective Rugged and Safe (QuEChERS) pesticide multiresidue method in combination with gas and liquid chromatography and tandem mass spectrometric detection. Analytical and Bioanalytical Chemistry, 389, 1697-1714.

22. SANCO/12571/2013,2013. Guidance document on analytical quality control and validation procedures for pesticide residues analysis in food and feed. Available online: http://ec.europa.eu/food/plant/ plant_protection_products/guidance_documents/ docs/qualcontrol_en.pdf (accessed 10.06.14).

23. Silva E., Daam M. A., José Cerejeira M., 2015. Aquatic risk assessment of priority and other river basin specific pesticides in surface waters of Mediterranean river basins. Chemosphere, 135, 394-402.

24. Singer H., Jaus S., Hanke I., Lück A., Hollender J., Alder A.C., 2010. Determination of biocides and pesticides by on-line solid phase extraction coupled with mass spectrometry and their behaviour in wastewater and surface water. Environmental Pollution, 158, 3054-3064.

25. Skoczko I., 2009. Attempts to use coal dusty for the disposal of pesticides in wastewater. Central Pomeranian Scientific Society for Environmental Protection, 11, 1307-1315.

26. Souza Caldas S., Rombaldi C., Oliveira Arias J. L., Cardoso Marube L., Gilberto Primel E., 2016. Multi-residue method for determination of 58 pesticides, pharmaceuticals and personal care products in water using solvent demulsification dispersive liquid-liquid microextraction combined with liquid chromatography tandem mass spectrometry. Talanta, 146, 676-688.

27. Svorc L., Rievaj M., Bustin D., 2013. Green electrochemical sensor for environmental monitoring of pesticides: Determination of atrazine in river waters using a boron-doped diamond electrode. Sensors and Actuators B, 181, 294-300.

28. Technical Learning College (TLC), 2012. Advanced Pest Control, continuing education professional development course. Advanced Pest Control, 11/15. 